\title{
POLYMORPHISM OF METHYLENETETRAHYDROFOLATE REDUCTASE (A1298C) AS A RISK FACTOR FOR OSTEOPOROSIS IN POST-MENOPAUSAL INDONESIAN WOMEN
}

\author{
ELZA IBRAHIM AUERKARI ${ }^{1,2 *}$, LINDAWATI KUSDHANY ${ }^{2,3}$, SRI SOFIATI UMAMI ${ }^{4}$, \\ TRI BUDI WAHYUNI RAHARDJO ${ }^{2,3}$, CHRISTOPHER TALBOT ${ }^{5}$
}

${ }^{1}$ Department of Oral Biology, Faculty of Dentistry, University of Indonesia, Jakarta, Indonesia. ${ }^{2}$ Centre for Ageing Studies, University of Indonesia, Depok, Indonesia. ${ }^{3}$ Department of Prosthodontics, Faculty of Dentistry, University of Indonesia, Jakarta, Indonesia. ${ }^{4}$ Department of Medical Biology, Faculty of Medicine, University of Indonesia, Jakarta, Indonesia. ${ }^{5}$ Department of Genetics, University of Leicester, Leicester, UK. Email: eauerkari@yahoo.com

Received: 26 May 2017, Revised and Accepted: 20 June 2017

\section{ABSTRACT}

Objective: The study aimed to assess the association between the A1298C polymorphism of the methylenetetrahydrofolate reductase (MTHFR) gene and risk to osteoporosis in post-menopausal Indonesian women.

Methods: After ethical approval, calcaneus bone mineral density (BMD) (T-scoring) was assessed from 194 consenting post-menopausal Indonesian women by dual-energy X-ray absorptiometry, and DNA of the participants was isolated from peripheral blood samples. To determine the status of A1298C polymorphism of MTHFR, isolated DNA was polymerase chain reaction (PCR) amplified in 35 cycles, to result in PCR product sizes of 302 bp (1298A) and $275 \mathrm{bp}$ (1298C). For fragment detection, the PCR product was subjected to electrophoresis on agarose gel. The results were statistically assessed for genotype and allotype comparison according to the T-score grouping by Chi-square analysis, assuming statistical significance at $\mathrm{p}<0.05$.

Results: The results show no significant association between the T-score (BMD) grouping and genotype (or allotype) of the tested polymorphism of MTHFR. The observed genotype distribution of the tested MTHFR polymorphism (A1298C) differs clearly from those previously reported, with AC as the dominant genotype in the Indonesian sample population of the present work.

Conclusion: The MTHFR (A1298C) polymorphism is relatively infrequent in the Indonesian female population, and no significant association was observed between this polymorphism, bone mineral density, and osteoporotic status.

Keywords: Menopause, Osteoporosis, Methylenetetrahydrofolate reductase, Polymorphism, Bone mineral density

(c) 2017 The Authors. Published by Innovare Academic Sciences Pvt Ltd. This is an open access article under the CC BY license (http://creativecommons. org/licenses/by/4. 0/) DOI: http://dx.doi.org/10.22159/ajpcr.2017.v10i10.20272

\section{INTRODUCTION}

Permanently reduced or lost post-menopausal ovarian activity and provision of the estrogen hormone will lead in the long run to faster rate of bone resorption than formation and thereby increasing risk to osteoporosis [1,2]. This metabolic bone disease is marked by reduced bone mineral density (BMD) and increasing microstructural deterioration and fragility of the bone. The incidence of osteoporosis increases with age and time after menopause and at a typical level of about $15-40 \%$ is a major hazard for aging post-menopausal women practically everywhere in the world [3-5]. While both environmental and inherited factors affect bone strength, twin and family studies suggest that genetic factors account for more than half of the variance in BMD [5]. The variation implies corresponding shifts in the network of regulatory genes that are involved in the balance between the osteoblastic bone formation and osteoclastic bone resorption and associated pathological conditions.

The methylenetetrahydrofolate reductase (MTHFR) gene localized at 1 p36.3 encodes for an enzyme that catalyzes the irreversible reduction of 5,10-methylenetetrahydrofolate to 5-methyltetrahydrofolate, a substrate for homocysteine remethylation to methionine. The involvement in homocysteine metabolism is thought to explain the adverse health impact of reduced enzyme activity by MTHFR polymorphisms [6]. The plasma homocysteine levels are affected by menopause, and for example, the C677T (rs1801133) polymorphism of MTHFR has been associated with increased skeletal fracture risk in postmenopausal women although not without some controversy [6,7]. It is therefore conceivable that other polymorphisms of this gene may carry an impact on the post-menopausal bone health. In particular, the other relatively common polymorphism A1298C (rs1801131) of MTHFR is known to result in the replacement of Glu- 429 by alanine, reduced MTHFR activity but no or only mild hyperhomocysteinemia $[8,9]$. The present work aims to clarify the relationship of A1298C polymorphism of MTHFR in post-menopausal Indonesian women and their risk to develop osteoporosis.

\section{METHODS}

In total, 194 consenting post-menopausal Indonesian women were included in the study. T-scoring by dual-energy X-ray absorptiometry (DXA) was used to characterize the calcaneus bone mineral density (BMD) of the participants. A T-score $<-2.5$ was taken to indicate osteoporosis, $-2.5 \leq \mathrm{T}$-score $<-1$ osteopenia, and T-score $\geq-1$ normal (healthy) level of BMD.

With these criteria, 72 (69 after dropouts during the genetic study) participants were included into the osteoporosis group, 59 (58) into the osteopenia group, and 63 (60) into the group of normal (healthy) participants. The study and applied methods were approved by the Ethical Committee of the University of Indonesia.

For DNA isolation, $3 \mathrm{~mL}$ of peripheral blood was collected from each participant and inserted into a tube $(15 \mathrm{~mL})$ containing red blood cell lysis solution (1.45 M NH4Cl, $5 \mathrm{mM}$ anhydrous EDTA, and $0.1 \mathrm{M} \mathrm{KHCO}_{3}$ ). The tube was repeatedly inverted and then incubated 
at room temperature for 10 minutes and centrifuged at $1500 \mathrm{rpm}$ for 10 minutes. The supernatant was discarded, leaving a deposit of mononuclear leukocytes. To this deposit, a cell lysis solution was added (10 mm Tris-HCL, pH 8.0, 0.5 mM EDTA, and 0.5\% SDS) and mixed by pipetting until homogeneous and incubated in water bath at $37^{\circ} \mathrm{C}$ for $30-60$ minutes. Then, $1.3 \mathrm{~mL}$ of a protein precipitation solution $(5 \mathrm{mM}$ ammonium acetate) was added, and the resulting product was vortexed for $15-20$ seconds and centrifuged at $3000 \mathrm{rpm}$ for 15 minutes at $4^{\circ} \mathrm{C}$. The supernatant was poured into a new Falcon tube containing cold isopropanol. The tube was inverted 20-30 times until the DNA precipitated as a collection of threads. The sample was then centrifuged at $3000 \mathrm{rpm}$ for 5 minutes at $4^{\circ} \mathrm{C}$. Supernatant was discarded, $70 \%$ ethanol was added to the pellet, and the mixture was centrifuged at $3000 \mathrm{rpm}$ for 5 minutes at $4^{\circ} \mathrm{C}$. Supernatant was discarded and the DNA was dried in open air by reversing the tube for more than $2 \mathrm{hrs}$. DNA was rehydrated with a solution of 200-300 mL TE (Tris-HCL EDTA) and incubated in water bath at $37^{\circ} \mathrm{C}$ for $2 \mathrm{hrs}$. The DNA solution was transferred to $1.5 \mathrm{~mL}$ sterile microcentrifuge tubes and stored at $-20^{\circ} \mathrm{C}[10,11]$

To determine the MTHFR polymorphism of A1298C loci, isolated DNA was amplified by polymerase chain reaction (PCR) mutation-selective method using two pairs of primers, forward primer CAAGGAGGAG CTGCTGAAGA TGTGGGGCCA GGAGCTGACC AGTGTAGA to detect 1298A and GGAGGAGCTG ACCAGTGATG C to detect 1298C. For both forward primers, the reverse pair was GACCCAGCCT GTCTTTGCCT. The PCR Kit KAPA2G Fast ReadyMix with dye was used. The solution included $10 \mu \mathrm{L}$ PCR Master Mix, $0.5 \mu \mathrm{L}$ of $10 \mu \mathrm{M}$ forward primer, and $0.5 \mu \mathrm{L}$ of $10 \mu \mathrm{M}$ reverse primers, and then, up to $6 \mu \mathrm{L} \mathrm{ddH}_{2} \mathrm{O}$ was added. The whole volume $18 \mu \mathrm{L}$ of each reagent is composed of genomic $1 \mu \mathrm{L}$ DNA and $17 \mu \mathrm{L}$ PCR mix. The DNA samples were amplified in 35 cycles including initial pre-denaturation at $95^{\circ} \mathrm{C}$ for 5 minutes, with the first cycle of denaturation at $95^{\circ} \mathrm{C}$ for 30 seconds, annealing at $63^{\circ} \mathrm{C}$ for 30 seconds, elongation at $72^{\circ} \mathrm{C}$ for 30 seconds, and final cycle extension at $72^{\circ} \mathrm{C}$ for 5 minutes. The MC-PCR products of $302 \mathrm{bp}$ and $275 \mathrm{bp}$ in length indicated the $1298 \mathrm{~A}$ and $1298 \mathrm{C}$ alleles, respectively.

For fragment detection, $5 \mu \mathrm{L}$ of PCR product in each well was subjected to horizontal electrophoresis at $60 \mathrm{~V}$ for 90 minutes on $1.5 \%$ agarose gel (Amresco) containing $1 \mu \mathrm{L}$ gel red (Biotium) in $1 \mathrm{X}$ TAE buffer solution (0.04 M Tris-acetate, 0.002 M EDTA, pH 8.0), using gel documentation for visualization and $50 \mathrm{bp}$ DNA ladder (Fermentas) for reference. The results were subjected to statistical assessment of genotype and allotype comparison according to the T-score grouping by Chi-square analysis, assuming statistical significance at $\mathrm{p}<0.05$.

\section{RESULTS}

The measured T-score is shown as a function of the time since menopause in Fig. 1, showing considerable scatter but a clear downward trend in the implied BMD. When grouped according to the interpreted scale from normal to osteoporosis, the corresponding increasing trend in the time since menopause is shown in Fig. 2. The results are shown in Table 1 as a comparison of genotypes (and allotypes) according to the mean T-score and grouping to normal participants and those with osteopenia or osteoporosis. The heterozygote AC genotype appeared as the dominant genotype, but the observed genotype is not in Hardy-Weinberg equilibrium ( $\mathrm{p}<0.00001$ in Chi-square testing).

\section{DISCUSSION}

As can be expected, the BMD (measured as T-scores of DXA) systematically decreases with the time after menopause. As also can be expected, a part of this is due to simultaneously increasing age of the participants (data not shown). Nevertheless, the scatter is large: While quite a few participants show osteoporotic T-scores only one year after menopause, there were also participants within the normal range of T-scores 20-25 years after the menopause (Fig. 1). The large scatter is also evident from Fig. 2, showing mean time ( \pm standard deviation) after menopause for the participants ranked into groups of healthy

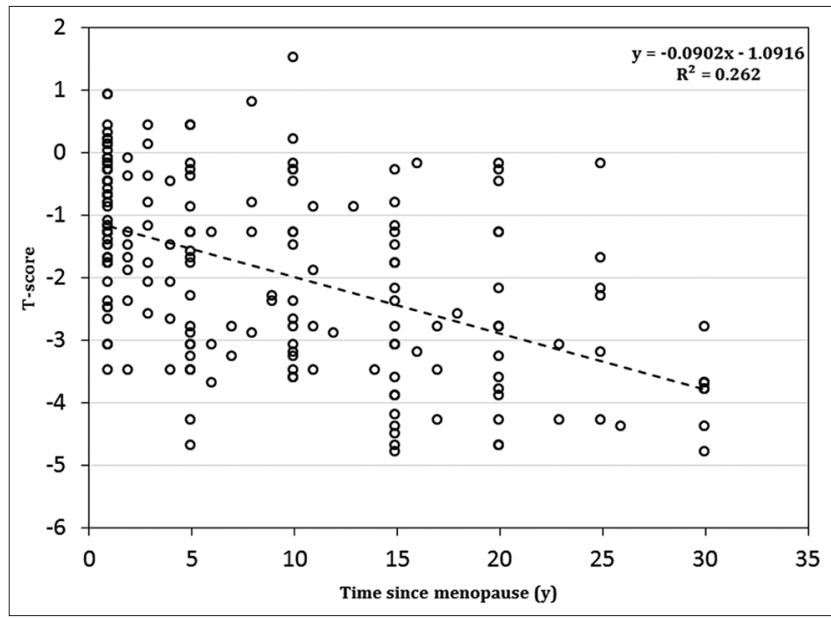

Fig. 1: T-score as a function of time after menopause, with linear regression line to show trend in bone mass density

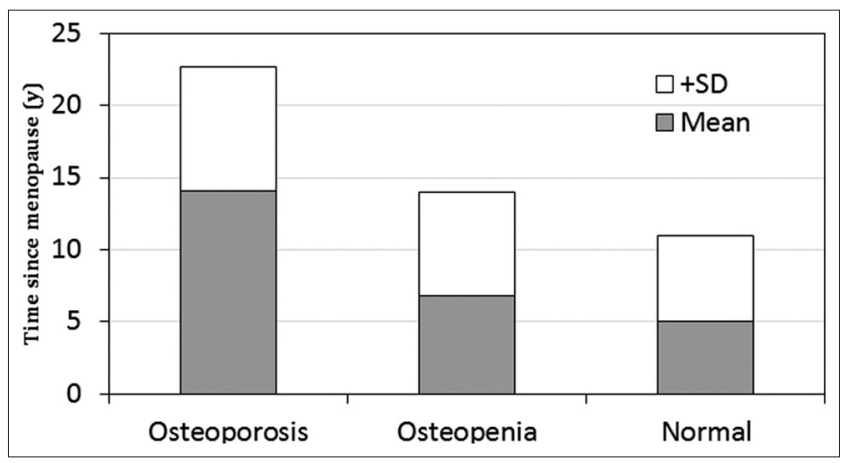

Fig. 2: Mean time after menopause for participants according to the T-score group

participants and those with osteopenia and osteoporosis. Probably due to the scatter, the trend of decreasing mean T-scores from genotype AA through genotype AC to genotype CC (Table 1) is not statistically significant. When classed into groups of normal participants and those with osteopenia and osteoporosis, there is no comparable systematic trend in the genotypes, largely because of the low number of AA and CC genotypes particularly in the osteopenia group. However, in the allotypes, the trend seems to reappear: The A allele becomes slightly but systematically less frequent from the normal to the osteoporosis group (Table 1). Hence, while the results do not show a statistically significant association between the T-score (BMD) grouping and genotype (or allotype) of the tested A1298C polymorphism of MTHFR, the observed underlying trend may become statistically significant with larger test samples.

The results also suggest that if the apparent protective nature of the A allele is real, it must be relatively weak. One reason for the apparent weakness in the tested Indonesian female population could be a countering trend of the possible advantage from a single C allele, demonstrated by the large fraction $(>80 \%)$ of the AC genotype. However, the observed genotype distribution of the MTHFR polymorphism (A1298C) clearly differs from the distributions reported for other world populations [8,9,12-15]. While, in general, agreement regarding the low fraction of the CC genotype (Table 2), the observed genotype distribution is not consistent with the Hardy-Weinberg equilibrium. This is not the most common outcome in studies on the A1298C polymorphism but has been reported for both Asian and Caucasian populations $[8,14,16]$. In any case, assuming that the CC genotype would carry some particular health impact, the low fraction of CC genotype means that to show a significant effect requires testing 
Table 1: Comparison of the number (\%) of genotypes and allotypes, T-scores and grouping to normal participants and those with osteopenia or osteoporosis

\begin{tabular}{|c|c|c|c|c|c|c|}
\hline \multirow[t]{2}{*}{ Grouping } & \multicolumn{3}{|l|}{ Genotype } & \multirow{2}{*}{$\begin{array}{l}\text { Total } \\
\mathbf{N}\end{array}$} & \multicolumn{2}{|l|}{ Alleles } \\
\hline & AA & AC & $\mathrm{CC}$ & & A & C \\
\hline Total N (\%) & $21(11.2)$ & 155 (82.9) & $11(5.9)$ & $187(100)$ & 197 (52.7) & $177(47.3)$ \\
\hline T-score mean & -1.78 & -1.91 & -2.13 & $187(100)$ & - & - \\
\hline Normal & $10(16.7)$ & $45(75.0)$ & $5(8.3)$ & $60(100)$ & $65(54.2)$ & $55(45.8)$ \\
\hline Osteopenia & $3(5.2)$ & 55 (94.8) & $0(0.0)$ & $58(100)$ & 61 (52.6) & $55(47.4)$ \\
\hline Osteoporosis & $8(11.6)$ & $55(79.7)$ & $6(8.7)$ & $69(100)$ & 71 (51.4) & 67 (48.6) \\
\hline
\end{tabular}

Table 2: Examples of observed genotype distributions of MTHFR polymorphism (A1298C); note here, the case and control populations have been combined; $\mathbf{p}>\mathbf{0 . 0 5}$ refers to compatibility with Hardy-Weinberg equilibrium

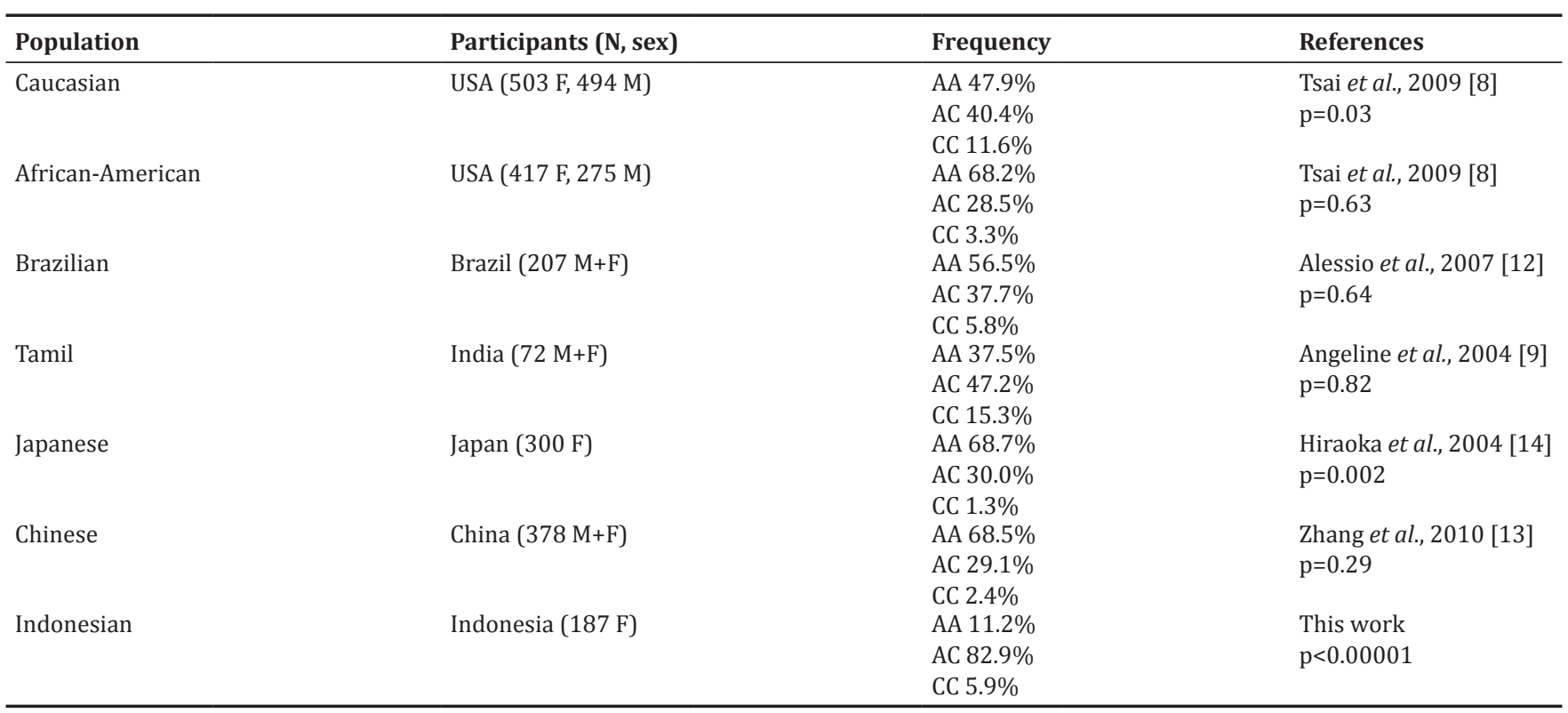

of a sizeable sample population, and this aspect would be similar for most world populations.

It should also be noted that any genetic effect of the MTHFR polymorphisms is unlikely to appear in isolation or independently from other genetic and environmental effects. In the case of the present study, likely compounding effects may be suspected from the processes of homocysteine metabolism, including, for example, the intake of riboflavin and folate $[12,13,17,18]$. The environmental effects from, for example, nutrition, exposure to sunlight, and other aspects of lifestyle will remain important also independently of population- and individualspecific genetic features $[19,20]$. Further work is suggested to clarify the interplay of the MTHFR polymorphisms and the environmental factors.

\section{CONCLUSION}

The results do not show a statistically significant association between the T-score (BMD) grouping and genotype (or allotype) of the tested A1298C polymorphism of MTHFR. The observed underlying trend may nevertheless become statistically significant with larger test samples.

\section{ACKNOWLEDGMENT}

The authors wish to acknowledge the financial support by the Ministry of Research, Technology and Higher Education through Directorate of Research and Public Service University of Indonesia.

\section{REFERENCES}

1. Raisz LG. Pathogenesis of osteoporosis: Concepts, conflicts, and prospects. J Clin Invest 2005;115(12):3318-25.
2. Duncan EL, Brown MA. Genetic studies in osteoporosis-the end of the beginning. Arthritis Res Ther 2008;10(5):214.

3. Rachner TD, Khosla S, Hofbauer LC. Osteoporosis: Now and the future. Lancet 2011;377(9773):1276-87.

4. Nelson HD. Menopause. Lancet 2008;371(9614):760-70.

5. Ralston $\mathrm{SH}$, de Crombrugghe B. Genetic regulation of bone mass and susceptibility to osteoporosis. Genes Dev 2006;20(18):2492-506.

6. Riancho JA, Valero C, Zarrabeitia MT. MTHFR polymorphism and bone mineral density: Meta-analysis of published studies. Calcif Tissue Int 2006;79(5):289-93.

7. Li D, Wu J. Association of the MTHFR C677T polymorphism and bone mineral density in postmenopausal women: A meta-analysis. J Biomed Res 2010;24(6):417-23.

8. Tsai MY, Loria CM, Cao J, Kim Y, Siscovick DS, Schreiner PJ, et al. Polygenic association with total homocysteine in the postfolic acid fortification era: The CARDIA study. Mol Genet Metab 2009;98(1-2):181-6.

9. Angeline T, Jeyaraj N, Granito S, Tsongalis GJ. Prevalence of MTHFR gene polymorphisms (C677T and A1298C) among tamilians. Exp Mol Pathol 2004;77(2):85-8.

10. Auerkari EI, Suryandari DA, Umami SS, Kusdhany LS, Siregar TW, Rahardjo TB, et al. Gene promoter polymorphism of RUNX2 and risk of osteoporosis in postmenopausal Indonesian women. SAGE Open Med 2014;2:2050312114531571.

11. Auerkari E, Suhartono A, Djamal N, Verisqa F, Suryandari D, Kusdhany L, et al. CRP and IL-1B gene polymorphisms and CRP in blood in periodontal disease. Open Dent J 2013;7:88-93.

12. Aléssio AC, Höehr NF, Siqueira LH, Bydlowski SP, Annichino-Bizzacchi JM. Polymorphism C776G in the transcobalamin II gene and homocysteine, folate and vitamin B12 concentrations. Association with MTHFR C677T and A1298C and MTRR A66G polymorphisms in healthy children. Thromb Res 2007;119(5):571-7.

13. Zhang C, Xie B, Fang Y, Cheng W, Du Y, Wang D, et al. Influence of 
maternal MTHFR A1298C polymorphism on the risk in offspring of schizophrenia. Brain Res 2010;1320:130-4.

14. Hiraoka M, Kato K, Saito Y, Yasuda K, Kagawa Y. Gene-nutrient and gene-gene interactions of controlled folate intake by Japanese women. Biochem Biophys Res Commun 2004;316(4):1210-6.

15. Yang B, Fan S, Zhi X, Xia R, Wang Y, Zheng Q, et al. Geographical and ethnic distribution of MTHFR gene polymorphisms and their association with diseases among Chinese population. Clin Genet 2017. DOI: $10.1111 /$ ege. 12929

16. Karmadonova NA, Shilova AN, Kozyreva VS, Subbotovskaya AI, Klevanets JE, Karpenko AA. Association of folate metabolism and pulmonary embolism: A case-control study of West-Siberian population. Thromb Res 2015;135:788-95.

17. Pols HA, Yazdanpanah Y, van Meurs JB. Homocysteine, the vitamin B complex family and bone. Int Congr Ser 2007;1297:151-7.

18. Bhaskar LV, Murthy J, Venkatesh Babu G. Polymorphisms in genes involved in folate metabolism and orofacial clefts. Arch Oral Biol 2011;56(8):723-37

19. Basu P, Sunny A, Maier C. Estrogenic and antiestrogenic activities of commercial dietary supplements containing herbal ingredients and is flavones. Int J Pharm Pharm Sci 2016;8:307-12.

20. Kumar PR, Joseph AK, Gokul G, Alex MP, Naveena G. Clinical outcome of calcium, vitamin D3 and physiotherapy in osteoporotic population in the Nilgiris district. Int J Pharm Pharm Sci 2016;8:157-60. 